\title{
Research on Leisure and Fitness Business Marketing and Market Structure
}

\author{
Haijuan Ren ${ }^{1}$ \\ ${ }^{1}$ Sias International University, Zhenzhou, Henan, 451150 \\ ${ }^{a}$ email
}

Keywords: Physical Fitness; Business; Market; Structure; Marketing; Zhengzhou

\begin{abstract}
In SCP paradigm and 7P.S marketing theory as the main theoretical basis, the use of interviews, field surveys and questionnaires and other methods to Zhengzhou for example, based on the city's sports and fitness business marketing, market structure and conduct investigation and analysis proposed amendments to the program is suitable for medium-developed central provinces, cities conduct marketing fitness business market structure. Currently, the city's sports and fitness market structure substantially types of monopolistic competition, pursuant to proposed amendments to the program should be based on the enterprise's own different economic capacity, to improve the policy on the basis of price competition, product strategy, advertising and other promotional the main way.
\end{abstract}

\section{Introduction}

So far, China's social and economic development shows a gradient feature eastern, central and western regions, the level of development of the eastern part of medium-sized cities is gradually approaching a moderately developed country. From the economic development of the current medium-developed eastern city of our country, its economic structure and level of development of sports and fitness market has basically the same configuration pattern. In 2005, the majority of medium-sized cities in eastern China's GDP in 3500 to 5 between 00 billion yuan, the proportion of tertiary industry is about 40\%; wherein, Zhengzhou City in 2005 GDP was 391.861 billion yuan, per capita GDP of 44,487 yuan, the tertiary industry accounting for $43.8 \%$; can be expected in

Future development, physical fitness eastern provinces of urban residents will form a new consumption areas. Based on this, the present study Zhengzhou City Fitness services as a study case, to study its market structure and corporate marketing practices.

\section{The Basis Theory and Research Methods}

In this paper, based on SCP Paradigm and 7P.S service marketing theory, according to three indicators determine market structure, Zhengzhou City, the gym project as the main content of the 25 sports and fitness business enterprise field investigation. SCP paradigm mainly by the market structure, market behavior and market performance of three basic components. Market behavior subject to market structure, market structure and reaction; market performance is the result of the market structure and market behavior interaction, it reflects the efficiency and resource configuration of the merits of the operation of the market, and through its implementation of relevant indicators by enterprise behavior changes or adjustments to promote changes in market structure. 7P.S service marketing theory 7 aspect consists of product, price, place, promotion, people, physical evidence and process control strategies. In this paper, its importance as a theoretical analysis of enterprise marketing activities and programs adjusted basis. 7P.S theory from the service industry characteristics of view, the industry's marketing practices and to give a more comprehensive discussion of the system. Staffing structure SCP paradigm and 7P.S service marketing theory questionnaires carried validity on the basis of expert investigation, its validity coefficient of 0.86 . After the Hangzhou area of 25 physical fitness companies investigated using statistical methods for data processing, the use of statistical software SPSS 11.0. 


\section{Fitness Enterprise Market Structure Analysis}

Market structure is characterized by a predetermined factor and constitutes market sellers (companies) to each other, each other between buyers and sellers as well as buyers and other groups such relationship [1]. Mainly from the market concentration, product differentiation and barriers to entry and exit these three areas to be judged. Market structure is divided into four major basic form, ie perfect competition, monopolistic competition, oligopoly and monopoly four kinds of market [2].

In this study, $G$ factor method to judge the degree of concentration of industrial economics, Lorenz curve and the vertical axis is related to the value (sales, value added, etc.) Cumulative percentage, the horizontal axis is the number of enterprises by size in ascending cumulative percentage [1]. When all companies within the industry are the same size, the Lorenz curve coincides with the diagonal. In general, the curve is convex to the lower right corner, indicating that the higher the degree of market concentration. G coefficient, ie Gini concentration coefficient, Lorenz curve is derived, is mainly used to reflect the size of the uneven distribution of the relative concentration index, its value between 0 and 1 change. If $A=0$, then $G$ coefficient is equal to 0 , equal distribution of firm size; if $B=0$, then $G$ factor equal to 1 , which means that there is only one company in the industry. $G$ coefficient smaller firm size distribution is closer to equality, $G$ factor, the higher the degree of market concentration. The formula is: $G=A$ / $(A+B)$ wherein, A-- Lorenz curve and the diagonal enclosed area; A + B-- below the diagonal triangle area. Look at the situation from the $G$ factor, Hangzhou Sports Fitness business focus gradually showing a trend, but not to the extent of oligopoly.

From the investigation that all businesses to provide Aerobics mainly, 54.55\% of the company offers a gym at least two types of projects; $36.37 \%$ of the companies also offer other fitness programs, such as ballet, karate, taekwondo, Sanda, Jeet Kune Do and swimming; 40.91\% of the enterprises, including beauty, body and other services; there are two companies set up squash project. Differences in terms of service, service attitude is better, but the personnel providing services, whether it is skills or professional knowledge and skills so there is a clear gap. Hardware, equipment, comfort and decorative differences arising due to large. In addition to individual manufacturers, most of the hours of operation is basically the same, and there is a certain relationship between enterprises and the number of members and sales.

Barriers to entering the market, along with the development of the market, new companies have been expanding into the small-scale enterprises to survive the difficulties. Space lease costs account for at least 50 per cent of expenditure, the larger renovation costs in the shop before the proportion accounted for. In addition, new entrants will face incumbent enterprise empt to have quality production resources, unfavorable financing, in particular barriers in loan interest and reputation, etc. [3]. Exit barriers, since special equipment is strong and difficult to sell, and an investigation has 30.43 percent of the enterprises are joint production, when you exit or quit affiliates, may be due to a problem or the effectiveness of the agreement on the credibility of other reasons, become exit sunk costs, resulting in economic losses. From the above three aspects, the Hangzhou Sports Fitness Market conditions: 1) the market has a large number of small enterprises, the output of each enterprise in the industry, only a small proportion of total production, a few large enterprises occupy a large market share, the data set of indicators showed that the market has focused on the characteristics; 2) despite gym gym project and non-project services and products have some differences, but the elasticity of substitution greater degree of change more frequently ; 3) low entry barriers in the industry, new companies can more freely enter the market, the cost of smaller companies out of the market when they pay, but already on the market to provide high-end services, or more upscale services continue to enter new businesses, service companies continue to provide low exit phenomenon. It can be judged, Hangzhou Sports Fitness monopolistic competitive market structure type.

\section{Physical Fitness Business Marketing Practices}

Market behavior refers to enterprises according to market competition structure, to win a greater 
margin of profit and market share taken by strategic activity [1]. Marketing behavior is an important part of market behavior.

In order to better analyze the behavior of corporate marketing, investment in this enterprise scale for physical fitness category: 0 registered capital to 99 million yuan; 100 to 199 million; $200 \sim 2.99$ million yuan; $300 \sim 3.99$ million yuan; 500 to 599 million; $600 \sim 6.99$ million yuan; 1000 yuan more than seven types (a registered capital of 400 to 499 million; $700 \sim 7.99$ million yuan; $800 \sim$ 8.99 million yuan; 900 to 999 million for the enterprise vacancy). From seven aspects of product positioning 7P.S theory, pricing, channel selection, sales practices, personnel policies, physical evidence and process control of the enterprise marketing behavior are discussed. Product strategy, statistics show that the scale of investment in 200 to more than 2.99 million yuan of enterprise products more obvious differentiation, product differentiation with registered capital, sales were positively correlated. Especially in the 3-7 type, 6 single type of enterprise portfolio, sales decreased significantly in the case of the overall rise

The second type of private education to provide comprehensive services and more than a single type, sales are slightly higher. Proved the existence of obvious differences in physical fitness enterprise product portfolio, the company's excess profits there may be a long time, due to the different business and financial capacity to pay consumers to price sensitivity and other factors, only at different levels to enhance the richness of product mix in order to effectively contribute to enhance profits. Price strategy, the environment, and limit the number of high-priced into the pricing, reputation and the use of discount pricing techniques, with different grades of Corporate Average sales growth and growth. Different pricing strategies and skills in different business groups will play a different effect. Within the scope of a certain grade, when the price behavior does not occur, the company's sales performance better. Such as 3 to 7 types, 6 types of enterprises with the only decline in the number of consumers and lower prices, sales also fell the most obvious. Price changes between the companies will attract the attention of consumers, have an impact on other businesses, or even a serious blow. Registered capital from small businesses instance, the price at the time of causing economic losses to the opponent, their own will also be affected. Visible, business trends and average sales price of a normal distribution were tested. When the product has advantages in terms of quality, variety, packaging, enterprises can

Higher price level on its sales, without losing all customers. Because some buyers prefer to pay a higher price, but also to buy quality or characteristics of the product. If there are companies trying to take small profits pricing strategy, can easily cause intra-industry business chain cut prices until a loss, it may stop price. Monopolistic competition industry, since many enterprises, the price difficult to reach agreement, so price competition is the main way of intra-industry competition monopoly enterprise competition. In addition, because people tend to buy products nearby, the company's location but also the formation of product differentiation and thus one of the important factors affecting the price [4], but its price behavior of different enterprises validity vary.

Marketing strategy, in addition to the fourth type of business, all companies have chosen personnel promotion, the first 4,5,6,7 types of enterprises have chosen business promotion, 4, 7 types of enterprises have chosen advertising . Different types of enterprises, the first type of enterprises selected sales promotion methods are mostly single-oriented enterprises, especially in the choice of the main promotion strategy; the second type select advertising and sales promotion way of a single type of enterprise is less than comprehensive, but sales volume also declined. Visible, using advertising and sales promotion strategies primarily more frequent business, sales are higher, that business sales and advertising, there is a high correlation between sales promotion behavior. Promotional market behavior as one of the important strategies 7P.S combination of policy, its manifestations are more abundant [3]. Including advertising, personal selling, sales promotion, etc. [5]. Monopolistically competitive market environment, enterprises should take as much as possible advertising or sales promotion, or a combination of both as the primary means of promotion. However, due to funding problems, the actual behavior of enterprises still differ. 
Monopolistic competition in the industry, the effectiveness of marketing activities has become a good corporate survival of important factors. From industrial organization theory describing market behavior concerning marketing has universal significance, combined sales of an important indicator of performance evaluation for the current market structure, have been proposed to alternative marketing programs. In order to more effectively carry out the program described herein is given first Framework Programme.

First, the return on the investment situation. Enterprises often financial capacity and the overall sales showed a certain correlation: Investment in 0 to 99 million in business during the year can basically get the same initial investment and financial flows, but less surplus; 100 to 1.99 million in investment enterprise yuan during the year can basically get the same initial investment and return on capital, surplus and get more than the former; $200 \sim 2.99$ million yuan investment in the company in addition to the initial investment can be recovered during the year the same cash flow, but also get more earnings; and 3 million yuan or more enterprises, since the first phase of investment compared to the long run, if the operation of enterprises well, it is possible to obtain a more substantial income. Second, the type. In the first phase of 0 to 199 million enterprise group (including new entrants enterprise), there are two types: 1) a single enterprise. The types of enterprises to provide yoga or shaping-based, low area requirements of the site, you can free up more funds for hardware configuration and decoration. Professional Yoga Pavilion usually in the form of small groups to provide services to customers, so that customers feel professional services psychologically. Due to the relatively high-end decoration and small-class service, the fee should be higher than the same integrated enterprise with a registered capital of a lot of sales are generally higher than the integrated enterprise. 2) integrated enterprises. The types of businesses charge a relatively low level due to limited funding, the level of service and facilities poor, unable to meet the feeling of comfort and consumption of customer requirements. The first phase investment of 200 million and above corporate group (including the new into the enterprise), the presence of more than a single integrated enterprise and enterprises. As companies begin invested sufficient funds, the advantages of a single enterprise weakened and disappeared even as a single core products at a disadvantage. Therefore, this type of business in more adequate funding areas are more difficult to obtain better returns. Investors according to their own circumstances, binding of different investment and return, choose a different location. Third, the environment. 1) In the main monopolistic competition, other morphological characteristics coexist in the market structure. From the business point of view the existence of a long time, different behavior at the same time produce different performance will have some impact on the market structure; just enter from the business point of view, to provide a larger service area also includes certain economic strength, and some companies have shown good momentum. 2) new entrants into the business and provide a higher alternative products. From the business point of view is about to enter the market, the greater the area, the main financial support ability. And a good part of the other parts of the operating results, financial strength, resources are more abundant in Hangzhou is planning to enter the fitness market. From a hotel, property and other projects, the company offers a gym investor business point of view, which are integrated enterprise, but there is a big difference in sales, with annual sales of less than most investment in the first phase of 0 to 99 million integrated enterprise.

Process control strategies: Process control is also known as process management, coordination of their overall activities, organizational activities, the policy relative to other strategies appear to be more stable, almost all businesses are expected to cost savings through its indirect sales increase performance. Therefore, in the discussion process in process control strategy, not distinguished companies. The whole process control around two main aspects: software: constantly improve the relevant rules and regulations, incentive-premise, in the process of developing regulations, the moderate tilt, encourage behavior toward staff adapted to change the direction of enterprise development. Emotional incentive-oriented, establish and regulate the duties of accounting consultants, hired personnel offer nutrition counseling services. Actively collect demand and suggestions of consumers, regular or irregular conduct of investigation or inquiry in writing, recording, summarizing, as the case may be processed, and the results fed back to the consumer in 
the form of written or oral. Hardware: always observe the safety equipment, equipment, regular maintenance of equipment, equipment. According to the needs of different products, projects and services, combined with funds, as far as possible the introduction of cost-effective, safe and good performance products, and on this basis

Looking on with the Company matching decorative products equipment. Economic strength of the enterprise may be appropriate in accordance with the requirements of membership, provide for rental equipment and other appliances for members activities.

In addition, with the development of enterprises in a monopolistically competitive market environment, when companies have a certain degree of monopoly power, with the size difference, spatial preemption and other conditions, it can be timely substantial price cuts. From the current actual situation of fitness business point of view, the existence of this kind of capability of enterprises. When it wants to rival out of the market or are intended to deter potential rivals to enter the area, it may take price cuts to be rivals out of the market after the price increases. Enterprises should be based on competition, new entrants and substitute products manufacturers situation, timely amend or add content target behavior, indirect guidance, revised product, price, place, promotion, people and physical evidence and other strategic behavior, market environment improve product profitability. Try between different enterprises to cooperate, a certain ability to take action against the equally competitive alternative products manufacturers, to reduce their threat. According to the bargaining power of suppliers, consumers, regulating corporate services and pricing, product and price of the enterprise in dynamic equilibrium. In short, through the maximum use of corporate resources, not only to achieve the purpose to enhance the economic efficiency of enterprises, but also to better optimize social benefits. By transforming corporate marketing behavior, reaction in the market structure. And attempt through cooperation and non-cooperative behavior strategies and improve new business entry barriers or the opponent's costs, reduce existing firms or their production costs in order to protect the best interests of existing enterprises.

\section{Conclusion}

At present, the country's eastern provinces fitness companies are in a monopolistically competitive market environment, each competitor will choose their own pricing and product strategies based on product differentiation and price competition. All aspects of marketing communications are produced in varying degrees, affect the performance of the company's sales, performance and behavior with different business situations change. Based on product differentiation and constantly enrich the product portfolio under, according to the environment, the number of qualified, reputable methods and techniques based discount pricing, advertising or sales promotion as the main marketing strategy; focusing on incentives and accounting consultants conduct internal marketing jobs establishment, physical evidence and process control strategies to effectively integrate all aspects of the strategy is to promote the effective conduct of the increase in sales. Central China between the middle developed areas, although there are differences, but because of the level of social, economic, cultural and other aspects of the development trend of similar, so that the study Case of Hangzhou ideas get strong support.

\section{Acknowledgements}

This is the initial results in 2014 in Henan Province Science and Technology Department of soft science and technology projects. Project Fund Number: 142400411307

\section{References}

[1] Yang Jianwen, Zhou Fengqi Industrial Organization: Theory Trend In The 21st Century [M] Shanghai: Academia Press, 2003.43.

[2] Tirole. Industrial Organization Theory [M] Beijing: China Renmin University Press, 1997.

[3] Qiu Bin. Marketing, The Basic Principles of A Classic Case [M]. Nanjing: Nanjing University 
Press, 2005.159,269.

[4] Tian Li. Investigation Sites, Investment Income And Current Situation Of The Gym Analysis [J] Physical Sciences, 2002,22 (3): 50-52.

[5] Feng Liyun. Photo-Service Marketing Process [M] Beijing: Economic Management Publishing House, 2002.169.

[6] Dennis Carlton, Jeffrey Alekperov Modern Industrial Organization [M]. Shanghai: Shanghai People's Publishing House, 1998.

[7] A Zesimaner Riel Guevara, Mary Jobitner Marketing Services [M] Beijing: Mechanical Industry Press, 2004.17.

[8] Donald Sea, De Warren Morris Industrial Economics And Organization [M] Beijing: Economic Science Press, 2001.489-590,11-20,184-192.

[9] Randall S, Schuler, Susan E Jackson. Linking Com-Petitive Strategies With Human Resource Management Practices [J] .Acad Exe, 1987, (3): 207-219.

[10] Lepak D, Snell S A.The Human Resource Architecture: To-Ward A Theory Of Human Capital Allocation Development [J] .Acad Manag Rev, 1999,24: 31-48.

[11] Cong Lake Level Sports Economics [M] Beijing: Higher Education Press, 2004.

[12] G Service Marketing Rochelle Perry [M]. Beijing: Foreign Economic And Trade University Press, 2000.

[13] Paul Samuelson, William Nordhaus Economics (16th Edition) [M]. Beijing: Huaxia Publishing House, 1999.

[14] Susan E Jackson, Rrandall S Schuler. Managing Human Resources Through Strategic Partnerships [M]. Beijing: Tsinghua University Press, 2004. 